Bangladesh J. Sci. Res. 28(2): 171-180, 2015 (December)

\title{
ARSENIC ACCUMULATION IN CROPS IN RELATION TO THEIR WATER REQUIREMENT
}

\author{
Sharmin Sultana ${ }^{1}$, Md. Harunur Rashid and S.M. Imamul Huq* \\ Department of Soil, Water and Environment, University of Dhaka, \\ Dhaka-1000 Bangladesh
}

\begin{abstract}
A pot experiment was conducted to study the transfer of arsenic (As) from soil to plant and to know the relation between arsenic accumulation and water requirement. The plants BR-29, BR-28, Red amaranthus (Lalshak) and Ipomoea aquatica (Kalmishak) were selected for this experiment. The control pots were irrigated with tap water and the treatment pots were irrigated with arsenic contaminated water. Different plant parts such as roots, straw, leaf and seeds of rice and roots, shoots, leaves of Lalshak and Kalmishak were analyzed. It was found that arsenic concentration was higher in the plants that were irrigated with arsenic contaminated water. Maximum arsenic concentration was found in roots and the minimum in leaves. The arsenic accumulation depended on the type of crops and varieties. The present study revealed that arsenic accumulation is higher in those plants that have higher water requirement. BR-29 needs more water than BR-28 and as a result BR-29 accumulated more arsenic than BR-28. Similarly Ipomoea aquatica accumulated more arsenic than Red amaranthus. From the experiment it was concluded that if irrigation is continued with arsenic contaminated water for a long time, arsenic may enter into the food chain beyond permissible limit and may cause human health risk.
\end{abstract}

Key words: Arsenic, water requirement, root zone, arsenic uptake

\section{Introduction}

The arsenic contamination in ground water is now a major environmental hazard and threat not only in Bangladesh but also in many countries of the world. Contamination of groundwater by arsenic in the deltaic region, particularly in the Gangetic alluvium of Bangladesh is one of the world's most important natural calamities (Imamul Huq and Naidu 2005). In some areas of Bangladesh, groundwater arsenic concentrations reach $2 \mathrm{mg} / \mathrm{l}$ (Tondel et al.1999). Between 30 and $40 \%$ of net cultivable land is under irrigation and more than $60 \%$ of this is met from groundwater. Presently, $75 \%$ of the total cropped area and $83 \%$ of the total irrigated area is used for rice (Oryza sativa L.) cultivation (Dey et al. 1996).

Imamul Huq and Naidu (2003) estimated the dietary load on the basis of arsenic content in Bangladesh rice grain. According to them about $19 \%$ of total population are under the possible exposure risk to exceed the maximum allowable daily level (MADL) value which is $0.2 \mathrm{mg} / \mathrm{day}$. The calculated daily human intake of arsenic from rice has been modeled for Bangladesh by

\footnotetext{
*Author for correspondence: <imamhuq@ hotmail.com>. 'IMMM, BCSIR, Joypurhat, Bangladesh.
} 
Meharg and Rahman (2003). According to them with a drinking water intake of $0.1 \mathrm{mg} / \mathrm{l}$ (which is considered highly elevated and a major health threat), arsenic intake from rice will account for 17.3 and $29.6 \%$ of As consumption if rice contained 0.1 and $0.2 \mu \mathrm{g} / \mathrm{g}$ of As, respectively. So arsenic from rice is an important pathway of exposure in Bangladesh food system.

In Bangladesh, people know that arsenic toxicity occurs because of drinking arsenic contaminated water from tube-well. It is true but tube-well water is not the only source of arsenic contamination in human body. This contamination also comes from food crops which are grown in the arsenic contaminated areas or in crops that are grown with arsenic contaminated irrigation water.

Quantifying uptake of As from soil by food crop and to investigate the effect of As accumulation in plant therefore, needs particular importance. The present study was carried out to ascertain the accumulation of arsenic in crop plants vis-à-vis their water requirements and to determine the sequestration of As in various parts including the edible parts. The crop plants chosen were: (a) Ipomoea aquatica, a leafy vegetable popularly known as "Kalmishak", an excellent source of vitamin A and fairly rich in vitamin $\mathrm{C}$, calcium, iron, potassium and phosphorus; (b) Red amaranthus (Amaranthus gangetica L.), another most common and popular leafy vegetable, locally known as "Lalshak" and (c) two most widely cultivated (irrigated) modern rice varieties viz., BR-28 and BR-29.

\section{Material and Methods}

Soil samples were collected from a cultivated land with the georeference of the sampling spot $23^{0} 54.776^{`} \mathrm{~N}$ and $90^{\circ} 10.938^{\circ} \mathrm{E}$. The soil thus selected (Fig 1: Location Map of the sampling site ) belongs to the soil series-Dhamrai; general soil type-non-calcareous grey floodplain soil (GST No.6); USDA soil taxonomy-typic Endoaquepts mixed, Non-acid and FAO (UNESCO Legend)Chromi-Eutric Gley sol.

The bulk of soil samples representing $0-15 \mathrm{~cm}$ depth from the surface were collected by composite soil sampling method as suggested by the soil survey staff of the USDA (1951). The collected soil samples were processed for chemical analyses as described in Imamul Huq and Alam (2005).

A pot experiment was carried out in the net house of the Department of Soil, Water and Environment, University of Dhaka. Water containing As (III) was used to irrigate the crops. The salt used for making the solution was sodium meta arsenite $\left(\mathrm{NaAsO}_{2}\right)$. The application rate was 1 ppm of arsenic. All experiments were done in triplicates. The pots were arranged in a systematic way in the net house. Two verities of rice seeds BR-28 and BR-29 were collected from the Bangladesh Rice Research Institute (BRRI). The variety of Red amaranthus seeds, namely BARI lalshak-1 was collected from the Bangladesh Agriculture Research Institute (BARI) and the variety of Kalmishak seeds Ipomoea aquatica were also collected from the same source. The background level of As in soil was $4.68 \mathrm{mg} / \mathrm{kg}$. This was taken as control. There were a total of 6 pots for each crop. Thus a total of 24 pots were used for this experiment. Earthen pots of 5 liter 
sizes were taken having no holes on the bottom. Each pot was filled with $4 \mathrm{~kg}$ soils. The control pots were irrigated with tap water only. The treatment pots were irrigated with As contaminated water. The whole of phosphorus, potassium and nitrogen doses except for rice as estimated for the soil were mixed with the soil. The sources of N, P and K were urea, TSP and MP.

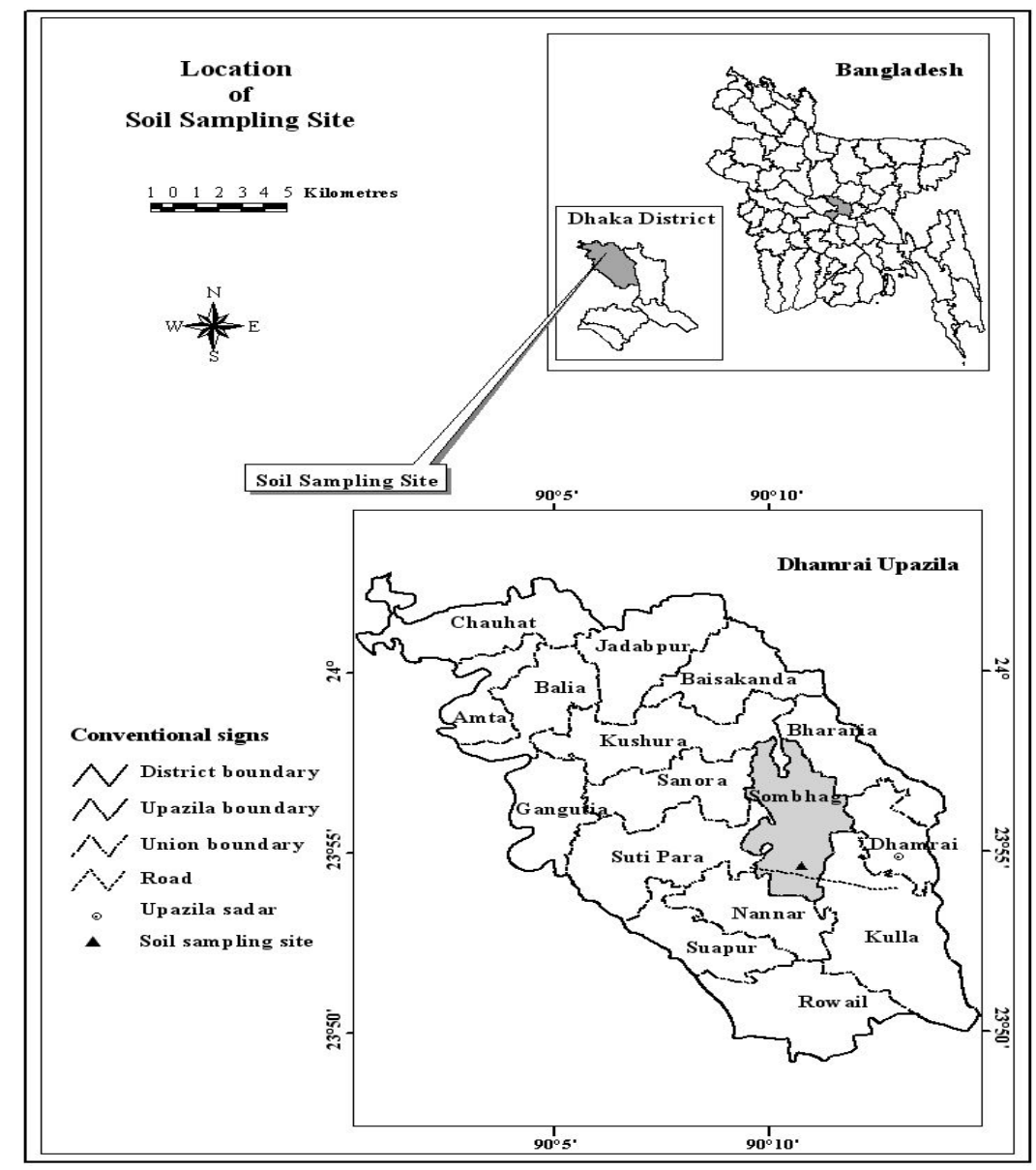

Fig 1. Location map of the sampling site.

Seeds of BR-28 and BR-29 were dipped in water and kept overnight and then sown in a seed bed for germination. When the seedlings became about $10 \mathrm{~cm}$ high, then these were sown directly in the pots. Six seedlings were sown in each pot. One-third of the required dose of urea was applied after 35 days and the final one-third was applied during panicle initiation stage of rice plant. Cultural operations were made whenever necessary. Weeds were removed manually. Agronomic characters like plant height, tiller numbers, panicle numbers, leaf color etc. were observed during the growth period. 
Seeds of BARI-Lalshak-1 were dipped in water and kept overnight and then sown directly in the pots and allowed to germinate under the hood of net house. After germination, when the seedling started to appear, the pots were then taken into the selected place of net house. The population was thinned to 10 plants after the seedlings were established. The same method was applied to Kalmishak. In case of Kalmishak, thinning was made to 5 plants after seedlings were established. Cultural operations and agronomic characters were maintained as it was for rice.

Plants of BR-28 and BR-29 were harvested by uprooting at the age of 120 and 130 days respectively. The harvested roots were washed with de-ionized distilled water three times to remove ion from the ion free space as well as to dislodge any adhering particles on the root surface. The upper parts of plants were also cleaned. The plant (rice) samples were separated into four parts: root, leaf, straw and grain. After taking fresh weight the collected plant samples were air dried and then oven dried at $70^{\circ} \mathrm{C}$ for 48 hours and the dry weight of plant samples were noted. The dried plant samples were then ground and were sifted through a $0.2 \mathrm{~mm}$ sieve. The ground plant samples of the two varieties were preserved separately. After harvesting, soil samples in each pot were collected. The same harvesting and preserving methods were followed for Lalshak and Kalmishak. These plant samples were separated into 3 parts as root, shoot and leaf.

The soil samples were analyzed in the laboratory for their physical, chemical and physicochemical properties following procedure as described in Imamul Huq and Alam (2005). The arsenic from the plant samples was extracted with $\mathrm{HNO}_{3}$ and from the soil (both pre- and post experiments) with aqua-regia solution (Portman and Riley 1964). The As in the extract was estimated by Hydride Generation -Atomic absorption spectrophotometer (HG-AAS). For every 10 samples a certified reference material (CRM) was included to ensure QC.

Statistical analysis of all collected data of the experiment was made by using commonly used statistical software Minitab14.2. The amount of As uptake (mg/100 plants) by different plant parts and the plant as a whole were calculated. The uptake was calculated using the As concentration in the dry matter and the dry weight of plant parts and the result was expressed as $\mathrm{mg} / 100$ plants:

Uptake (As) $=$ Concentration (As) in dry matter $\times$ dry weight of plant part.

\section{Results and Discussion}

The collected soil sample was analyzed in the laboratory before set up of the experiment to see the nutrient status of the soil. Some important soil properties are presented in Table 1.

The growth of plants in both control and treated soil was more or less similar initially. The vegetative growth of rice (both BR-28 and BR-29) was good in the first two months but after that the older leaves become yellowish. It could be due to either to the shortage of sulphur or the attack of insects. After using insecticide, the yellow colorings were stopped. The vegetative growth of Red amaranthus and Ipomoea aquqtica were good. At the last stage, insects attacked the leaf of Red amaranthus and Ipomoea aquqtica. But other than that no special symptoms were observed. 
Red amaranthus: The fresh yield from the treated (1 ppm of As solution) soil (351.9 gm/100 plants) was better than its control soil $(312.8 \mathrm{gm} / 100$ plants). But for Ipomea aquqtica some exceptions were seen i.e., in treated soil (1226 gm/100 plants) yield was lower than its control soil (1613.2 gm/100 plants). For BR-28, the fresh yield from the treated soil (1153.33 gm/100 plants) was better than its control soil (957.5 gm/100 plants). In case of BR-29 lower yield (1483.17 $\mathrm{gm} / 100$ plants) was obtained than its control soil (1532.83 gm/100 plants) with As treatment. It appears that the rice varieties had differential response to the presence of arsenic in irrigation water. BR-28 seemed to have a better tolerance than BR-29. Similar observations have been made by Imamul Huq et al. (2006).

Table 1. Some physical, physicochemical and chemical properties of the soil.

\begin{tabular}{ll}
\hline Soil properties & Value \\
\hline Particle size analysis & \\
Sand & $4.58 \%$ \\
Silt & $67.93 "$ \\
Clay & $27.49 "$ \\
Textural class & Silty clay \\
$\mathrm{pH}$ & 6.4 \\
$\mathrm{EC}$ & $0.065 \mu \mathrm{s} / \mathrm{cm}$ \\
Organic carbon & $0.87 \%$ \\
Field capacity & $37.81 \%$ \\
Moisture content & $26.13 "$ \\
Total $\mathrm{N}_{2}$ & $0.132 "$ \\
Available $\mathrm{N}_{2}$ & $50.10 \mathrm{ppm}$ \\
Total-P & $0.05 \%$ \\
Available-P & $3.3 \mathrm{ppm}$ \\
Total potassium & $0.31 \%$ \\
Available-K & $0.107 \mathrm{ppm}$ \\
Arsenic & $4.68 "$ \\
Fe & $1 \%$ \\
\hline
\end{tabular}

The average dry weights of the four types of plants were calculated in gm/100 plants. The dry weights were: Red amaranthus (control - $433.33 \mathrm{gm}$ and treated - $441.00 \mathrm{gm}$ ), Ipomoea aquatica (control - $201.00 \mathrm{gm}$ and treated - $155.53 \mathrm{gm}$ ), and BR-28 (control - $204.33 \mathrm{gm}$ and treated $235.50 \mathrm{gm}$ ), BR-29 (control - $358.67 \mathrm{gm}$ and treated - $306.33 \mathrm{gm}$ ). ANOVA test indicated that for only BR-28 its variance was significant at $1 \%$ level in straw and at $100 \%$ level in root. For the Red amaranthus, the dry matter yield from the treated soil (1 ppm of As solution) was better than its control soil. But for Ipomoea aquatica dry matter yield was lower than its control soil. For 
BR-28 the dry matter yield from the treated soil was better than its control soil. In case of BR-29 arsenic treatment caused a lowering of the dry matter yield.

\section{Arsenic accumulation in plants:}

Accumulation of arsenic by different crops and their water requirements are presented in Table 2. The mean values of arsenic concentrations in root, straw, leave and grain of BR-29 and BR-28 are shown in Figs 2 and 3 respectively. The mean values of arsenic concentrations in Lalshak and Kalmishak are presented in the Figs 4 and 5 respectively.

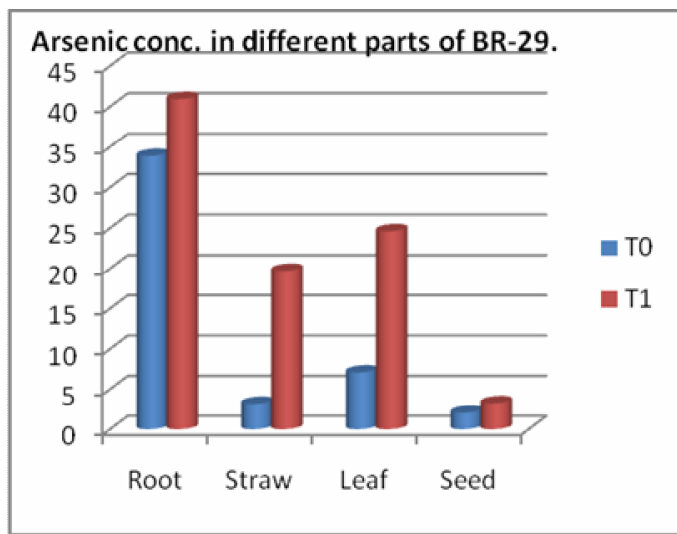

Fig. 2. Arsenic concentration in different parts of BR-29.

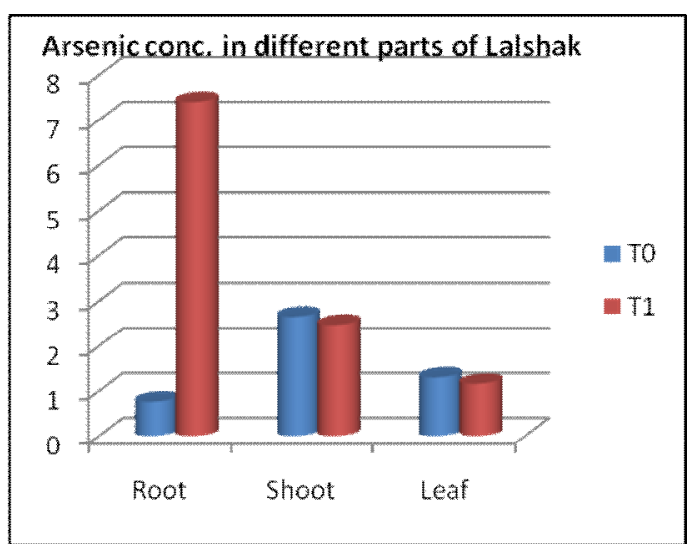

Fig. 4. Arsenic concentration in different parts of Red amaranthus (lalshak)

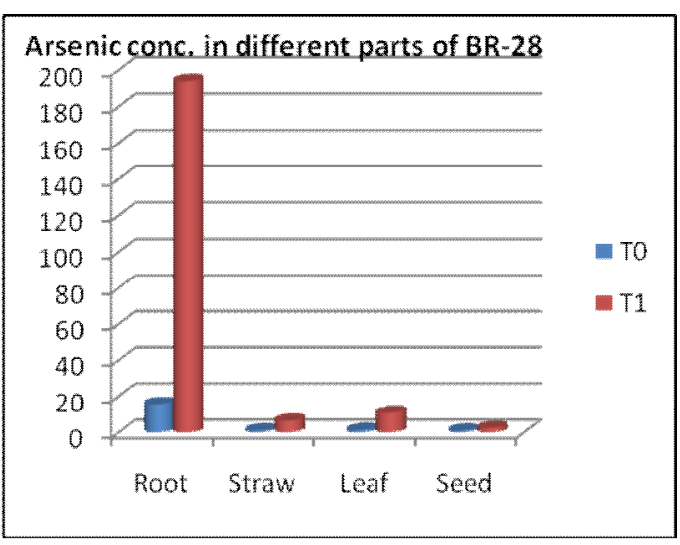

Fig. 3. Arsenic concentration in different parts of BR-28.

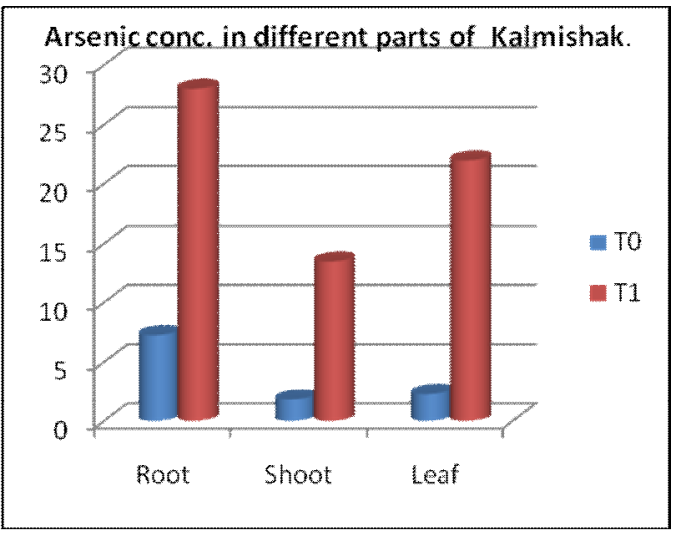

Fig. 5. Arsenic concentration in different parts of Ipomoea aquatica (kalmishak).

\section{Rice:}

Leaf: The leaves of BR-29 accumulated $(24.6 \mathrm{mg} / \mathrm{kg}$ in treated soil) higher amount of arsenic than those of BR-28 (10.99 mg/kg in treated soil). Both the varieties accumulated higher concentration of As than their corresponding control (leaves of BR-29 $7.07 \mathrm{mg} / \mathrm{kg}$ and BR-28 $1.52 \mathrm{mg} / \mathrm{kg}$ ) indicating the fact that As in water enters into the irrigated rice plants. 
Straw: The straw of BR-29 accumulated comparatively higher amount of arsenic (19.70 $\mathrm{mg} / \mathrm{kg}$ ) compared to the straw of BR-28 $(6.61 \mathrm{mg} / \mathrm{kg})$ indicating the fact that the latter variety is more As resistant than the former one. Similar observation was also noted by Imamul Huq et al. (2006). In control condition straw of BR-29 $(3.16 \mathrm{mg} / \mathrm{kg})$ accumulated a little higher As than that of BR-28 $(1.31 \mathrm{mg} / \mathrm{kg})$.

Grain: The grains accumulated comparatively smaller amount of arsenic than the other parts in both the varieties. BR-29 grains accumulated $3.24 \mathrm{mg} / \mathrm{kg}$ while the grains of BR-28 accumulated $2.56 \mathrm{mg} / \mathrm{kg}$ of As in treated soil. In control soil BR-29 grains accumulated (2.02 $\mathrm{mg} / \mathrm{kg})$ higher As than BR-28 $(1.20 \mathrm{mg} / \mathrm{kg})$. It is further proven that of the various organs, the rice grains accumulate the least amount of arsenic. However, the amount of rice consumed per capita in Bangladesh along with arsenic contaminated water and other foods may largely surpass the MADL (Correll et al. 2006)

Root: Roots accumulated higher amount of As than other parts of plant in both varieties. The observation that arsenic in rice plants is mostly sequestered in roots (Imamul Huq et al. 2006) has been substantiated in our study too. The BR-28 roots contained $194.09 \mathrm{mg} / \mathrm{kg}$ of As while the roots of BR-29 contained $40.93 \mathrm{mg} / \mathrm{kg}$ under treated condition.

\section{Lalshak and Kalmishak:}

Leaf: Kalmishak leaves accumulated higher amount of arsenic $(21.94 \mathrm{mg} / \mathrm{kg})$ than Lalshak leaves $(1.17 \mathrm{mg} / \mathrm{kg})$. In this experiment Lalshak leaves contained lower arsenic than its corresponding shoot and root. In case of Kalmishak, the leaves contained higher arsenic than its shoot.

Shoot: Lalshak shoot accumulated $(2.66 \mathrm{mg} / \mathrm{kg})$ higher arsenic than Kalmishak shoot $(1.87$ $\mathrm{mg} / \mathrm{kg}$ ) under control condition. But under treatment condition Kalmishak shoot $(13.52 \mathrm{mg} / \mathrm{kg})$ accumulated more arsenic than Lalshak shoot $(2.48 \mathrm{mg} / \mathrm{kg})$.

Table 2. Accumulation of arsenic by plants and their water requirements.

\begin{tabular}{lccc}
\hline Plants & Treatment & $\begin{array}{c}\text { Arsenic accumulation } \\
(\mathrm{mg} / \mathrm{kg})\end{array}$ & $\begin{array}{c}\text { Water requirements } \\
(\mathrm{L})\end{array}$ \\
\hline BR-29 & T0 & 13.45 & 29.6 \\
& $\mathrm{~T} 1$ & 37.58 & 29.6 \\
BR-28 & $\mathrm{T} 0$ & 12.53 & 27.73 \\
& $\mathrm{~T} 1$ & 33.78 & 28.6 \\
Red amaranthus & $\mathrm{T} 0$ & 2.59 & 7.90 \\
& $\mathrm{~T} 1$ & 2.87 & 8.30 \\
Ipomoea aquatica & $\mathrm{T} 0$ & 13.43 & 8.33 \\
& $\mathrm{~T} 1$ & 20.06 & 8.8 \\
\hline
\end{tabular}

Root: Treatment of soil with arsenic solution increased its concentration in root over control in both the vegetables. Kalmishak roots contained higher amount of arsenic than Lalshak. Root arsenic concentration of Lalshak $(7.41 \mathrm{mg} / \mathrm{kg})$ was higher in treated plant than control $(0.77$ $\mathrm{mg} / \mathrm{kg}$ ). Whereas Kalmishak roots contained $7.27 \mathrm{mg} / \mathrm{kg}$ As in control and $28.02 \mathrm{mg} / \mathrm{kg}$ As in treated plants. This is an indication that Kalmi is a hyper accumulator for arsenic. 
Vegetables have a shorter life time (average 30 days) and rice has a longer life time (average 150 - 160 days). The vegetables need smaller amount of water (Table 2) as compared to rice. At the same time it was observed that different plant parts of leafy vegetables (Lalshak and Kalmishak) accumulated smaller amount of arsenic and different plant parts of rice (BR-28 and BR-29) accumulated larger amount of arsenic. The relation between As accumulation and water requirement is shown graphically in Fig. 6.

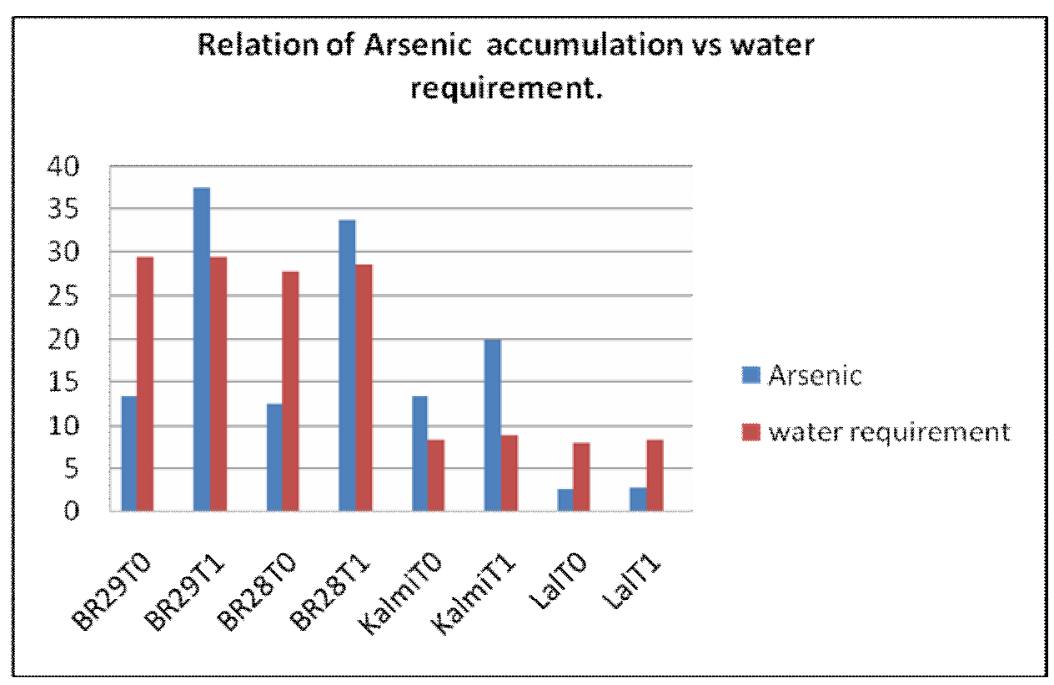

Fig. 6. Relation of As accumulation vs water requirement.

\section{Uptake of arsenic:}

The ANOVA test indicates that there is a positive interaction between treatment of arsenic and different variety of plants. In case of BR- 29, the p value is significant at $100 \%$ level and in Kalmishak, the $\mathrm{p}$ value is significant at $5 \%$ level. But the $\mathrm{p}$ values for other varieties are not significant. The arsenic uptake by different varieties of plants is shown in Table 3 .

Table 3. Arsenic uptake by different types of plants.

\begin{tabular}{lcccc}
\hline \multirow{2}{*}{ Treatment } & \multicolumn{3}{c}{ Crops } \\
\cline { 2 - 5 } & $\begin{array}{c}\text { BR-29 } \\
(\mathrm{mg} / 100 \text { plants })\end{array}$ & $\begin{array}{c}\text { BR-28 } \\
(\mathrm{mg} / 100 \text { plants })\end{array}$ & $\begin{array}{c}\text { Ipomoea aquatica } \\
(\mathrm{mg} / 100 \text { plants })\end{array}$ & $\begin{array}{c}\text { Red amaranthus } \\
(\mathrm{mg} / 100 \text { plants })\end{array}$ \\
\hline T0 & 4.815 & 2.560 & 2.69 & 0.112 \\
T1 & 11.517 & 7.955 & 3.129 & 0.127 \\
\hline
\end{tabular}

\section{The correlation between water requirement and arsenic uptake}

The purpose of this study was to find any correlation between arsenic uptake and water requirement. From the present study it has been found that there is a positive correlation between 
arsenic uptake and water requirements for all the crops. For BR-29 $r=0.58(\mathrm{p}=0.232)$, for BR-28 $r=0.59(p=0.215)$, for Lalshak $r=0.81(p=0.093)$ and for Kalmishak $r=0.36(p=0.490)$. When all the crops were considered together it was found that the $\mathrm{p}$ value is significant at $1 \%$ level although for individual cases the $\mathrm{p}$ values were not significant.

\section{Conclusion}

From the present study it is found that when water requirement is high then arsenic uptake is high. But this uptake varies again according to the variation of crop types and varieties. Kalmishak accumulated higher amount of arsenic than Lalshak and BR-29 accumulated higher amount of arsenic than BR-28 did. From the present findings it is clear that the plant which needs more water also accumulates more arsenic. Arsenic accumulation in plants differed not only between the four species; but it varied also among the different plant parts of the four species as well. It can thus be concluded that when plants receive As-contaminated water, the accumulation of As in the particular plant will depend on its genetic make-up and the water requirement. As such it is suggested that one should properly select a plant if it has to be grown in arsenic affected areas with arsenic contaminated water. This will minimize the risk of exposure to Arsenic contamination through food chain.

\section{Acknowledgements}

The authors would like to acknowledge the Bangladesh Australia Centre for Environmental Research (BACER-DU), University of Dhaka, for providing Laboratory facilities and financial assistance for doing this research work.

\section{References}

Correll, Ray, S. M. Imamul Huq, E. Smith, G. Owens and Ravi, Naidu. 2006. Dietary intake of arsenic from crops. In: Managing Arsenic in the Environment: From Soil to Human Health, R Naidu, E smith, G Owens, P Bhattacharya and P Nadebaum (eds.). CSIRO Publishing, Melbourne, Australia. pp. 255-271.

Dey, M. M., M. N .I. Miah, B. A. A. Mustafi and M. Hossain. 1996, Rice production constaints in Bangladesh : Implication for further research priorities. In : Evenson R E, R W Heardt, M Hossain, (eds.) Rice research in Asia : Progress and priorities. CAB international, Wallingford, UK, and International rice research institute, Manila, Philippines, pp. 179-191.

Imamul Huq, S. M. and R. Naidu, 2005. Arsenic in ground water and contamination of the food chain: Occurrence, remediation and management. Bundchuh, Bhattacharya and Chandra Shekharam(eds.). A. A. Balkema publishers, NewYork. pp. 95-101.

Imamul Huq, S. M., J. C. Joardar, S. Parvin, Ray, Correll and Ravi, Naidu. 2006. Arsenic contamination in food chain: Transfer of arsenic into food materials through groundwater irrigation. J. Health Popul. Nutr. 24(3): 305-316.

Imamul Huq, S. M., U. K. Shila and J. C. Joradar. 2006. Arsenic mitigation strategy for rice by water regime management. Land Contamination and Reclaimation 14(4): 805-813. 
Imamul Huq, S. M. and M. D. Alam (eds). 2005. A Handbook on Analysis of soil, plant and water. BACERDU, University of Dhaka, Bangladesh, xxii+ 246 pp.

Imamul Huq, S. M. and R. Naidu. 2003. Arsenic in ground water of Bangladesh : contamination in the food chain. In : M Feroze Ahmed (ed.), Arsenic contamination : Bangladesh perspective. ITN-Bangladesh; Centre for water supply and management. BUET, Dhaka, Bangladesh.

Meharg, A. A. and M. M. Rahman. 2003, Arsenic contamination of Bangladesh paddy field soils: implications for rice contribution to arsenic consumption. Evaluation Sci. Technol. 37: 229-234.

Portman, J. E. and J. P. Riley, 1964. Determination of arsenic in sea water, marine plants and silicate and carbonate sediments. Anal. Chem. Acta. 31: 509-519.

Quaghebeur, M. and Z. Rengel. (2001). The presence of arsenate in the rhizosphere of canola plants affects the uptake of phosphate from goethite and kaolinite. Soil Science and Plant Nutrition, Faculty of Agriculture. The University of Western Australia, Nedlands, Western Australia.

Wallace, A., R. T. Mucller and R. A. Wood. 1980. Arsenic phytoxicity and interactions in Bush bean plants grown in solution culture. J. Plant Nutrition 2: 111-116.

(Manuscript received on December 05, 2015; revised on December 26, 2015) 